\title{
Geostatistical Analysis of well Velocity Data for Enhanced Depth Imaging in the Niger Delta
}

\author{
G. I. Alaminiokuma and W. N. Ofuyah \\ Department of Earth Sciences, Federal University of Petroleum Resources Effurun, P.M.B. 1221, Effurun, \\ Warri, Nigeria
}

\begin{abstract}
Velocity analysis was conducted in, Agbada Field, onshore Niger Delta using geostatistical tools. This provided a quantitative technique of integrating interval velocities from Checkshots and Sonic Logs for 60 wells with the two-way travel time from 3-D pre-stacked seismic image data for an identified reservoir (D5.2). Analyses by crossplots, regression plot with variogram modelling, and kriging produced results useful in improving on some of the associated limitations arising from spatial data continuity, anisotropy and azimuthal properties inherent in velocity data. Besides, error term analysis, poor correlation between primary and secondary data, and improper calibration of data from various sources result in poor depth estimate. Geostatistical velocity analysis facilitates enhanced estimation and better depth conversion. This will improve the existing structural framework necessary for the quantification of bypassed hydrocarbon and possible redevelopment of the fields in the Niger Delta, Nigeria.
\end{abstract}

Keywords: Geostatistics, Velocity, Variogram, Anisotropy, Sonic Log, Seismic data, Checkshot, Niger Delta.

\section{Introduction}

Velocity modelling for depth conversion has been identified as one of the sources of seismic uncertainties in fields in the Niger Delta. The quality of time-to-depth conversion is dependent on the quality of the velocity prediction. A prospect can be "made or broken" depending on how "optimistically" or "pessimistically" velocities are derived and employed in depth conversion. Accurate velocities prediction is necessary to properly characterize reservoirs and optimize the placement of development wells.

Depth imaging is the preferred seismic imaging tool for today's most challenging exploration and reservoir-delineation projects. In areas of structural or seismic velocity model complexity, many of the assumptions underpinning traditional time-domain processing are invalid and can produce misleading results. Typical situations might be heavily faulted sequences or salt intrusions. In these cases, only the careful application of 3D prestack depth imaging can be relied on to accurately delineate geological structure, aiding risk assessment, and helping operators to improve drilling success rates (Schlumberger, 2017).

Depth conversions are problematic due to the large number of variables that influence velocities, making it nearly impossible to derive the "correct" velocity solution and the corresponding depth structure. The non-uniqueness of classical velocity models affects depth conversion. These models are based mainly on empirical or regression formulas of well logs or seismic data. Such approaches treat data as spatially independent observations and ignore the existence of spatial patterns. Velocity determination by well logs based only on regression models suffers some problems due to the sparsity of wells. More so, determination by seismic data has limitations associated with noise, phase error, poor resolution among others.

Since a unique velocity solution by the classical methods is apparently not reliable, this paper highlights the improvements that can be obtained through a geostatistical analysis of velocity variability. This will allow the examination of data uncertainty and an interpretation of a range of solutions to offer improved geologic description for the quantification of the remaining hydrocarbon and possible redevelopment of the various fields in the Niger Delta.

\section{Geologic Background}

The Niger Delta Basin is located in Southern Nigeria between latitudes $3^{\circ} \mathrm{N}$ and $6^{0} \mathrm{~N}$ and longitudes $4^{0} 30^{1} \mathrm{E}$ and $9^{\circ} \mathrm{E}$. The delta covers an area of about $105,000 \mathrm{~km}^{2}$. The Niger delta is a large arcuate delta of the destructive wave dominated type and is divided into the continental, transitional and marine environments. A sequence of under compacted marine shale (Akata formation, depth from $11121 \mathrm{ft}$. Paleocene in age) is overlain by paralic or sand/shale deposits (Agbada formation, depth from 7180-11121ft, Eocene to Pleistocene in age) are present throughout. The paralic interval is overlain by a varying thickness of continental sands (Benin formation, depth from 0-6000ft, Oligocene to Recent in age). The Akata shales are mobile, undercompacted and typically overpressured. They are considered to be the main source rock of the Niger Delta with the upper part considered matured source rock. Weber and Dakorou (1975). The Akata formation formed during lowstands in sea-level and in oxygen deficient conditions. (Tuttle et. al., 2015). The Akata shales are mobile, undercompacted 
and typically overpressured. The Agbada Formation comprises marine facies defined by both freshwater and deep sea characteristics. The hydrocarbons in this layer formed when this layer of rock became subaerial and was covered in a swamp type of environment that contained lots of organics (Weber, 1987). This is the major oil and natural gas bearing facies in the Basin. Growth faults strongly influenced the sedimentation pattern and thickness distribution of sands and shales. The Benin formation contains no commercial hydrocarbons although several minor oil and gas stringers are present (Avbovbo,1978). Hydrocarbon is trapped in many different trap configurations. Oil and gas are trapped by roll-over anticlines and growth faults (Weber,1987). Stratigraphic traps are also known to exist in the Niger Delta. (Merki, 1972) noted that the age of the Formations become progressively younger in a down-dip direction and ranges from Paleocene to Recent. The Niger Delta Basin is very complex, and it carries high economic value as it contains a very productive petroleum system. The Basin produces around 2 million barrels of oil per day. The entire system is predicted to contain 34.5 billion barrels of oil and 94 trillion feet ${ }^{3}$ of natural gas. This area is still very heavily explored by oil companies today and it is one of the largest oil producers in the world (Tuttle et. al., 2015).

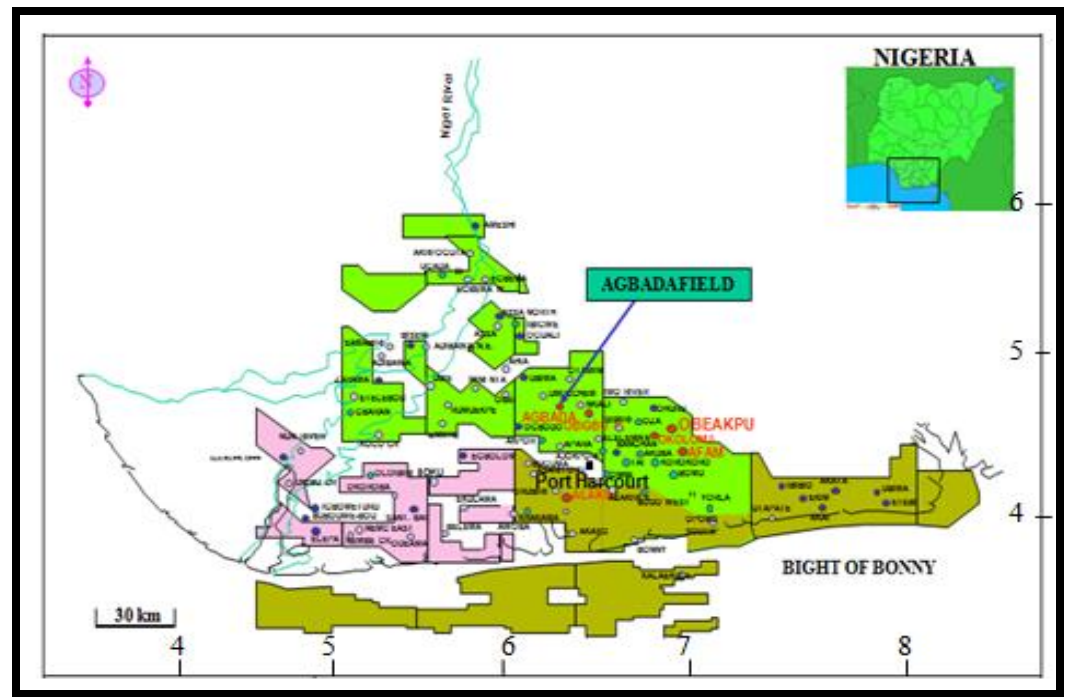

Figure 1: Map Showing the Study Area, Agbada Field, Niger Delta

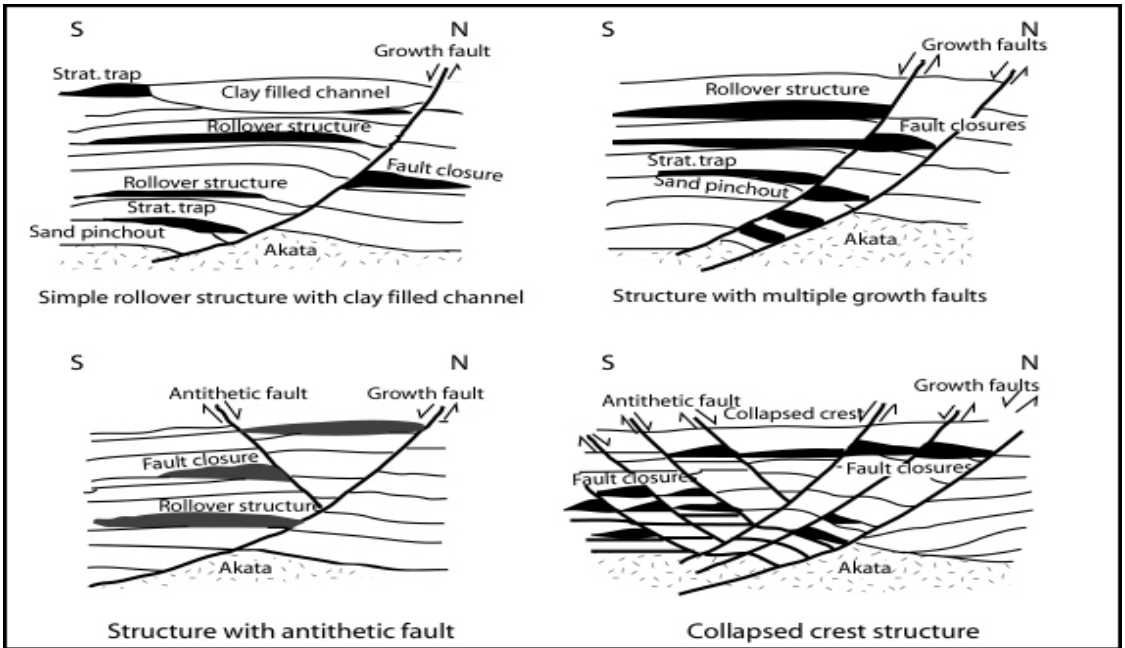

Figure 2: Examples of Niger Delta oil field structures and associated trap types (Modified from (Doust \& Omatsola, 1990) and (Stacher, 1995)

\section{Classical Velocity Modelling for Depth Conversion}

\section{Theory}

Depth conversion of seismic time data requires building a numerical model of the subsurface velocity field. The velocity data that goes into this model is derived from various sources such as Checkshots (VSP) and Sonic logs, and indirect measurements such as seismic processing velocities, preferably "as-picked" stacking velocities after DMO (Coleou, 2001). 
The conventional velocity modelling techniques utilized, particularly by some geophysicists undertaking depth conversion, for so many years now has been functions derived mainly from well logs. Velocity models from well data use statistically established equations (empirical or regression formulas) that describe the vertical changes in velocity, as they are naturally available from this particular spatial sampling (Coleou, 2001).

Stacking velocities have traditionally been regarded as less precise, and have only been preferred in those cases where lateral velocity variations are dominating. They provide complementary information to understand and model these velocity changes. Shallow gas sands, seabed scarp or mud diapirism may generate strong overburden velocity anomalies. These large lateral velocity gradients induce time distortions at the target horizons. It is necessary to remove them to infer anomaly-free overburden velocity model and to properly assess compaction coefficients or gradients (Armstrong et al., 1999). This can better be resolved by a geostatistical velocity analysis for depth conversion.

\section{Geostatistical Velocity Analysis for Depth Conversion}

Geostatistics is increasingly used to "map" spatially correlated data (Chambers et al., 2000) during velocity model building for all kinds of depth conversion. "Geostatistics offers a way of describing the spatial continuity of natural phenomena and provides adaptations of classical regression techniques to take advantage of this continuity" (Isaaks and Srivastava, 1990).The theoretical basis of geostatistics has been fully described by several authors (Journel, 1989; Isaaks and Srivastava, 1990; Goovaerts, 1997; Dubrule, 1998; Hohn, 1998). The main tools in geostatistics are the variogram (semi-variogram), which expresses the spatial dependence between neighbouring observations, and kriging, the "best linear unbiased estimator." Variograms crossplot variance (a measure of data variability) and distance to obtain a mathematical relationship for the kriging function. Kriging uses a mathematical model of the spatial correlation of data along with known data values to estimate values between or beyond known points.

The variogram (semivariogram), $\gamma(h)$, can be defined as one-half the variance of the difference between the attribute values at all points separated by $h$ as follows:

$$
\gamma(h)=\frac{1}{N(h)} \sum_{i=1}^{N(h)}\left[Z\left(x_{i}\right)-\left(Z\left(x_{i}+h\right)\right)\right]^{2}
$$

Where $\mathrm{Z}(\mathrm{x})$ indicates the magnitude of variable, and $\mathrm{N}(h)$ is the total number of pairs of attributes that are separated by a distance $h$.

Spherical, Exponential, Gaussian, and Pure nugget effect are the most commonly used variogram models that allow the computation of a variogram value for any possible sampling interval prior to geostatistical estimation (Isaaks and Srivastava, 1990). The Spherical model is probably the most commonly used model of all. It has a linear behaviour close to the origin, but flattens off at larger separations, reaching a sill at the range $a$. This is an intermediate roughness model.. It is used when in doubt (Francis, 2002). The variograms obtained through cross-validation satisfy the minimum acceptance criteria for geostatistical analysis (Leuangthong et al., 2004).

Kriging technique is an exact interpolation estimator used to find the best linear unbiased estimate. This must have minimum variance of estimation error. Detailed discussions of kriging methods and their descriptions can be found in Goovaerts (1997). The general equation of kriging estimator is:

$$
Z^{*}\left(x_{p}\right)=\sum_{i=1}^{n} \lambda_{i} Z\left(x_{i}\right)
$$

Where $Z^{*}\left(X_{p}\right)$ is the kriged value at location $x_{p}, Z\left(x_{i}\right)$ is the known value at location $X_{i}, \lambda_{i}$ is the weight associated with the data. There are several forms of kriging developed for estimation purposes. The estimation algorithms most commonly used are the following: Simple kriging (SK); Ordinary kriging (OK); Universal kriging (UK); Kriging with external drift (KED); Cokriging and collocated cokriging; Indicator kriging Indicator and collocated cokriging (Lima, 2005).

Kriging with external drift (KED) is employed for depth conversion in this work since it allows the use variograms and a guiding data set (usually seismic attributes) to grid well data. In this procedure, the seismic attributes (seismic times), the external drift, guides the kriging process to introduce a component of its trend into the estimated velocities. The seismic times are introduced as additional constraint in the calculation of optimal weights (Hwang and Mc-Corkindale, 1994). 
Some Limitations of the Classical Velocity Modelling Techniques and the Improvement by Geostatistical Analysis

Biased Results by Classical Statistics

Classical statistics treats well data as single-point data leading to biased results in the presence of low frequency lateral variations in velocity for large layers. A close observation of the contoured interval velocities at the various well locations shown in Figure 11 reveals a number of "anomalous" velocities with poor spatial correlation. This problem could be completely ignored by regression models employing well data only and this certainly will not allow for proper delineation and interpretation of the lateral velocity variations on the D5.2 horizon, hence poor depth conversion. Kriging, the "Best Linear Unbiased Estimator" (BLUE) properly addresses this problem. The Kriging with External Drift (KED) algorithm mostly suitable for depth conversion is employed here. In this procedure, the seismic time data (the external drift) guides the kriging process to introduce a component of its trend into the estimated velocities. The seismic data are introduced as an additional constraint in the calculation of the optimal weights. Since kriging with an external drift assimilates more information into the estimation process, it is expected to provide better results than classical regression models for the Agbada field data set.

\section{Poor Correlation Coefficient by Linear Regression Model}

Whilst the linear regression with error residual approach has served the industry well over the years, it suffers the limitations of assuming the correlation coefficient between the primary and secondary data to be 1.0 (unity). This may not be true all the time. Figure 13 shows a correlation coefficient of 0.008 calculated for a cross plot of interval velocities and seismic two-way time by linear regression analysis only in this Field. This very low correlation coefficient means lack of confidence in the predictions employing regression models only.

\section{Wrong Error Analysis}

The "error" determined by the classical regression model is not an error term, but is in fact the uncertainty between the primary and secondary variables and this uncertainty is often ignored. With the geostatistical kriging algorithm, combined with linear regression an account of this is taken.

\section{Limitations due to Noise in Velocity Attributes}

There is the need to filter the seismic velocities as a result of noise. Geostatistics, through variogram decomposition and factorial kriging, designs spatial filters very efficient for the removal of organized noise present in seismic velocities. The smoothing procedure is based on horizontal consistent velocity Fields to preserve the location of the velocity contrast. It also preserves the changes due to compaction prior to smoothing in order to retrieve the meaningful low frequency lateral variations.

\section{Poor Seismic-to-well calibration}

Various sources of information need to be integrated with heterogeneous quality and quantity, and geostatistical techniques like kriging with external drift, Co-located Cokriging or Bayesian kriging exist to do so. However, special care should be taken when dealing with highly biased well data sets, ruling out automatic application. The impact of correction maps to honour the wells should also be evaluated as it may destroy previous modelling and analysis work.

\section{Use of indirect Measurements}

Impact information from highly deviated wells and horizontal wells does not yield direct velocity measurements but localized constraints bounding the model. Introducing inequality constraints during kriging is possible and ensures multi-layer consistency with available data.

\section{Uncertainty Assessment}

No matter how much effort put in the classical velocity modelling, our depth prediction will be inaccurate. We need to assess the uncertainties in the model building. Geostatistics, with stochastic simulations, provide the necessary framework to assess the precision of a given depth surface estimate and evaluate the incidence of non-linear operations like reserve prediction or split between licenses

\section{Method}

Figure 3 is a workflow algorithm for depth conversion using the classical velocity modelling approach. The velocity models are constructed in layers, separated by interpreted surfaces. Velocities for the different layers are calibrated to wells. Homogeneity or smooth transition is assumed in between wells. Such models are very precise when these assumptions are met, and they preserve thickness in thin layers very well. When velocity varies laterally, the preferential well spatial sampling often leads to biased results. Figure 4 is a 
workflow algorithm for depth conversion using geostatistical velocity analysis. The adequacy and validity of the developed variogram model is tested by cross-validation. This consists of removing a data at a time from the dataset and re-estimating this value from remaining data using different variogram models. Interpolated and actual values are compared, and the model that yields the most accurate predictions is retained. Cross-plotting the estimated against the true value shows the correlation coefficient $\left(\mathrm{R}^{2}\right)$. The most appropriate variogram is chosen based on the highest correlation.

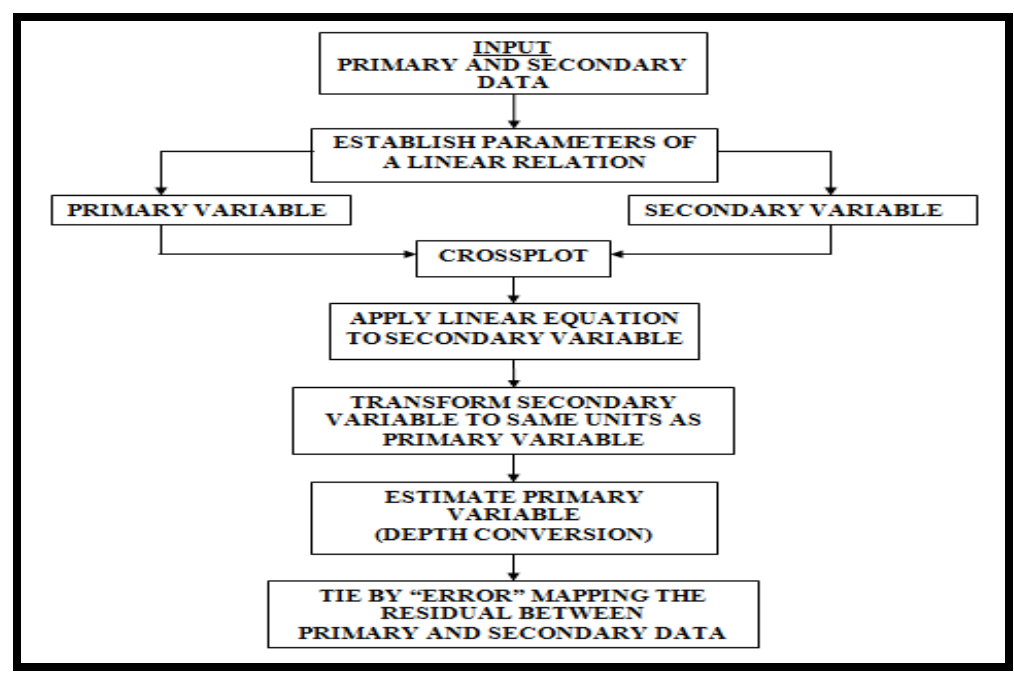

Figure 3: Workflow Algorithm for Depth Conversion by Linear Regression-Based Velocity Modelling

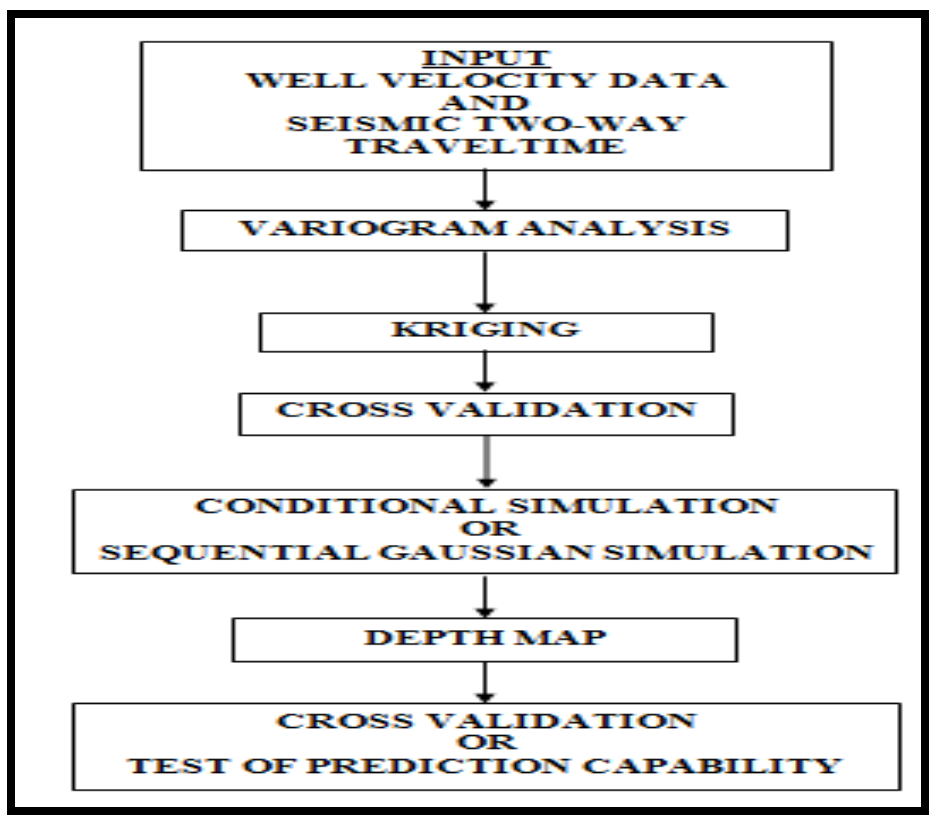

Figure 4: Workflow Algorithm for Depth Conversion for Depth Conversion by Geostatistical Velocity Analysis

\section{Field Data Example In The Niger Delta}

An example from the Agbada Field located in the onshore Niger Delta of Nigeria (Figure 1) is used to illustrate a typical geostatistical velocity analysis revealing some of the limitations in employing the classical velocity models for depth conversion.

3-D Pre-Stacked Image seismic (PSI) data volume covering the field was interpreted with LANDMAK'S SEISWORK ${ }^{\mathrm{TM}}$ software to delineate reservoir tops (Figure 5). Well information was interpreted and tied with seismic data to accurately determine the reservoir top (Figure 6). Seismic time map (Figure 7) was generated for the interpreted top of D5.2 reservoir. Interval Velocities were calculated from the sea level to the top of the D5.2 reservoir for 60 wells from Checkshot and Sonic log data in the field using SCHLUMBERGER'S PETREL ${ }^{\mathrm{TM}}$ software. The interval velocities calculated at 60 well locations for the top of D5.2 reservoir are shown in Figure 8. Figure 9 shows interval variation with depth in a typical well in the field, while Figure 10 shows interval velocity and two-way time cross plot. 
Investigating these interval velocities geostatistically, numerous spherical-variogram types were modelled for the top of the D5.2 reservoir in different orientations, and the ones chosen to define the mathematical variability of the data are shown in Figures 11 and 12. In the direction of maximum variability, the variogram was interpreted to have a Sill or maximum variance of $1.0225(\mathrm{~m} / \mathrm{s})^{2}$ and a Lag distance (range) of $2100 \mathrm{~m}$. In the direction of minimum variability, the variogram was interpreted to have a Sill of 0.1941704 $(\mathrm{m} / \mathrm{s})^{2}$ and a range of $2100 \mathrm{~m}$. The different Sills but same range of the variograms shows that the interval velocity is zonally Anisotropic (i.e., the variability changes with directional orientation within the field). This means that the interval velocity has a spatial pattern laterally. The variogram model is now used as an input to guide the kriging process. An ordinary contour map treating these interval velocities as single data points is shown in Figures 13. Figures 14 and 15 show the maps of the interval velocities after applying the kriging algorithm only first, and then considering the effect of external (time) drift (KED) in SURFER 8.0 Software. The maps of the corresponding depths are shown in Figures 17 and 18. In Figure 15, the highly prospective zones are in Geen colour,followed by Yellow and Orange colours. This is in view of the velocity pull-down in the presence of hydrocarbon. This indicates the epicenter or the drill point which facilitates well placement. Differences such as lithofacies variation, indicating enhancment,are better defined on kriging with external drift maps than on maps of raw and kriged data.The depth map (Figure 18) is indicative of a slope.

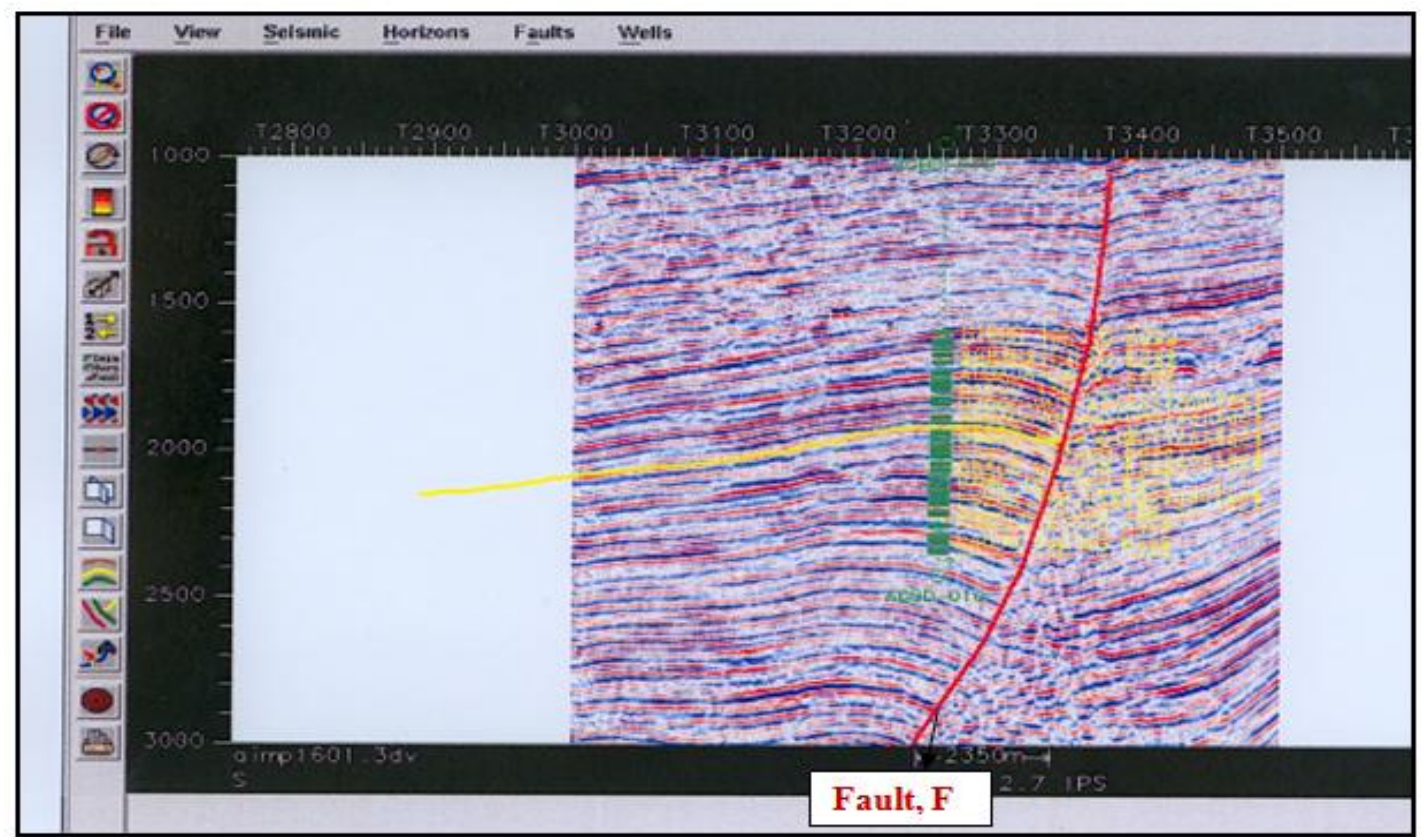

Figure 5: Agbada Field: Seismic Line Interpretation Showing D5.2 Horizon

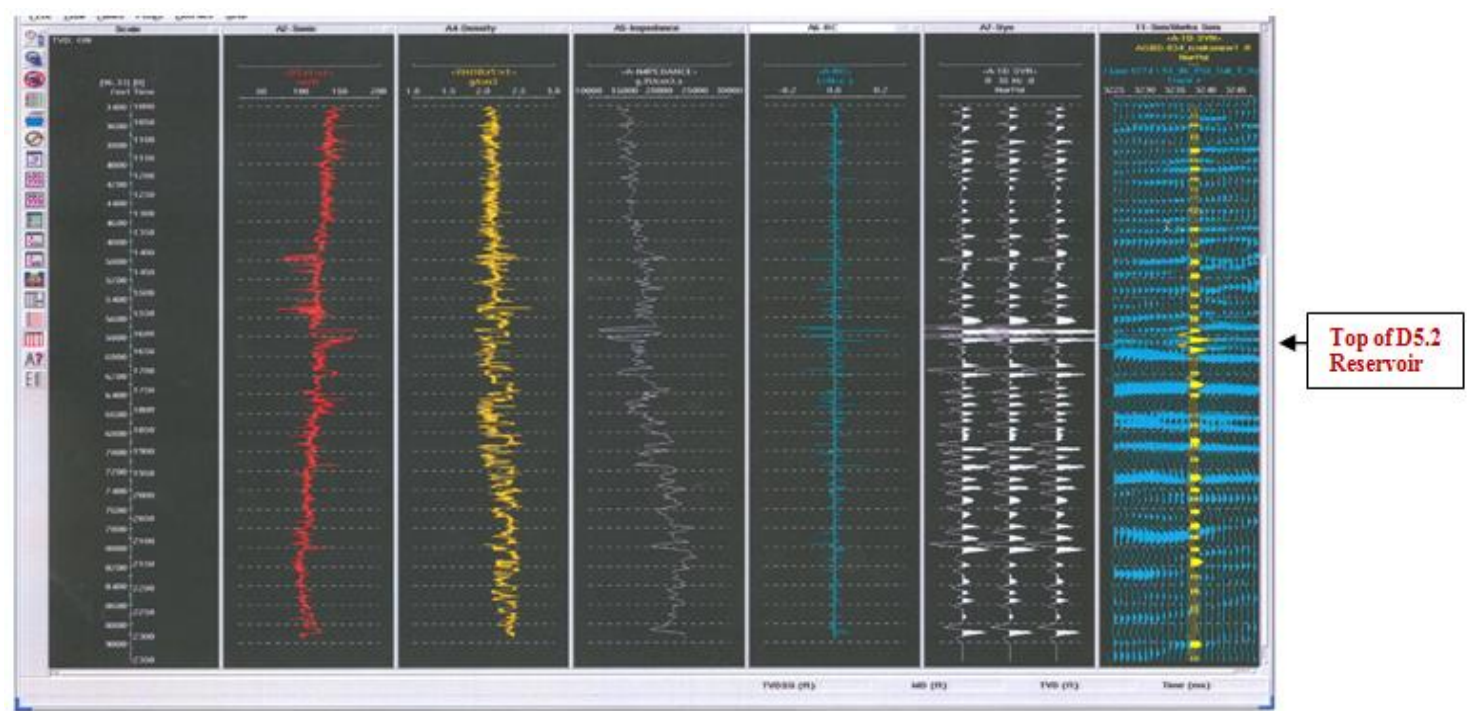

Figure 6: Agbada Field: Well-to-Seismic Tie for Well "X" showing the top of D5.2 Reservoir 


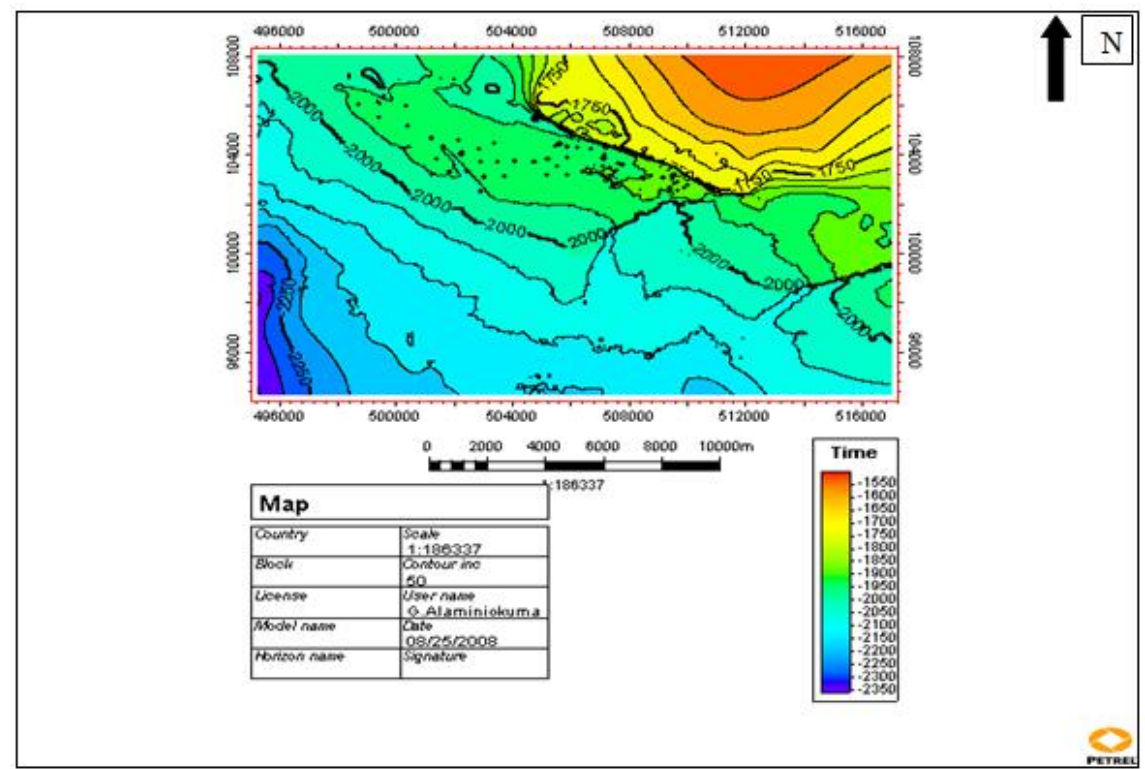

Figure 7: Agbada Field: Seismic Time Map of the Top of D5.2 reservoir.

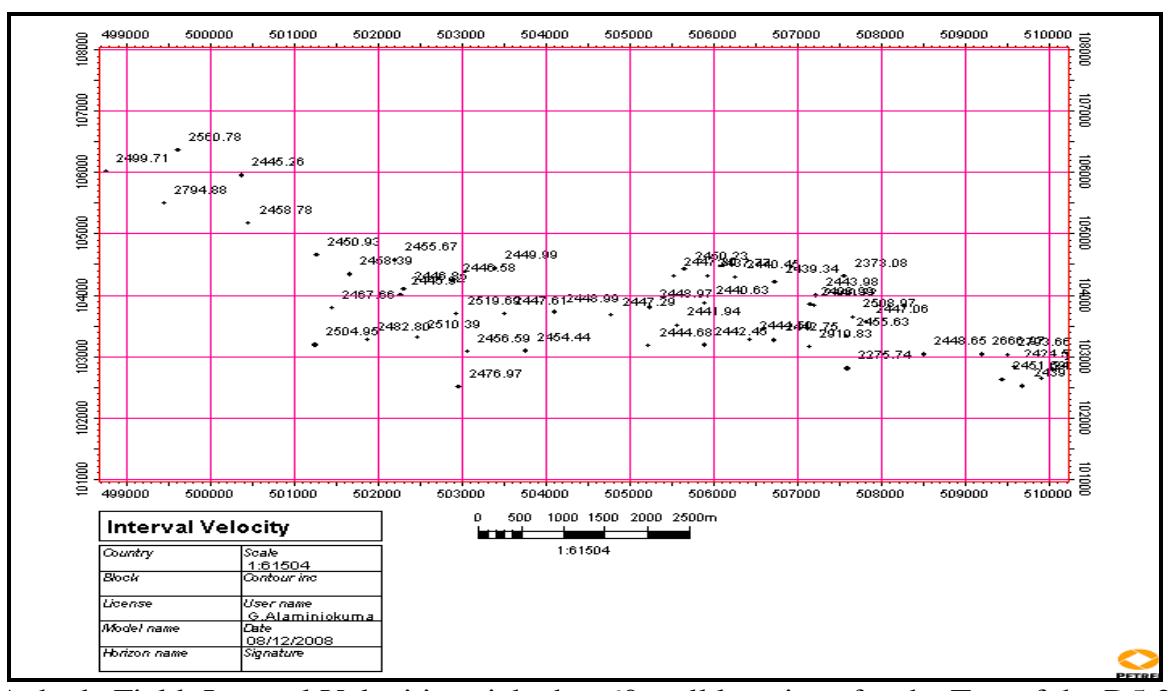

Figure 8: Agbada Field: Interval Velocities picked at 60 well locations for the Top of the D5.2 Reservoir

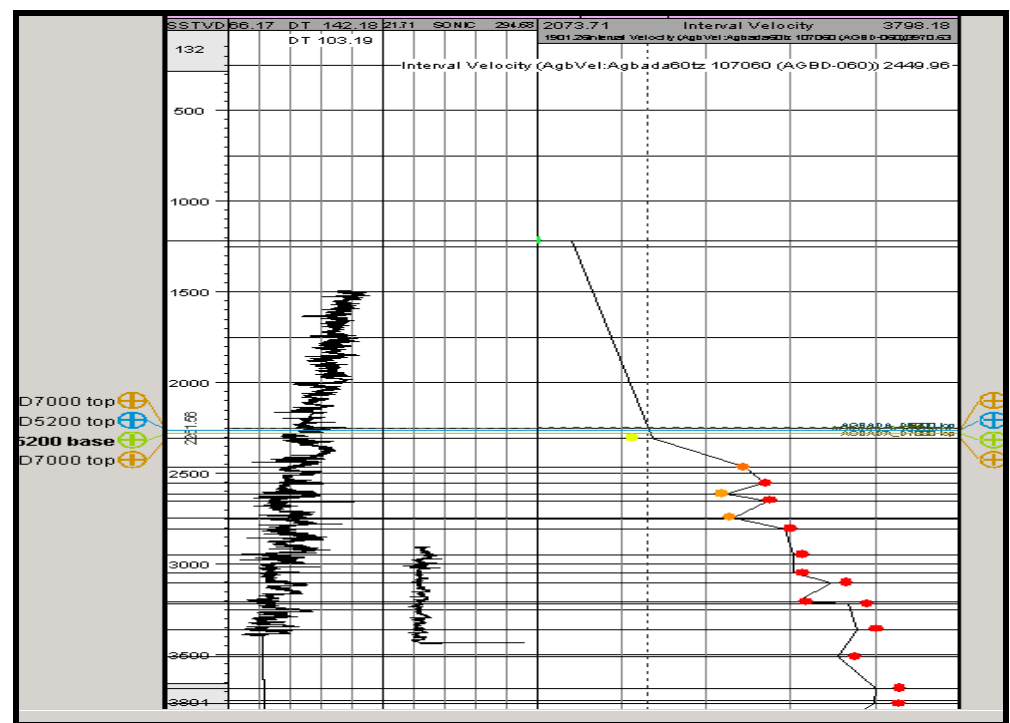

Figure 9: Agbada Field: Interval Velocity at the Top of D5.2 Reservoir in a typical well 


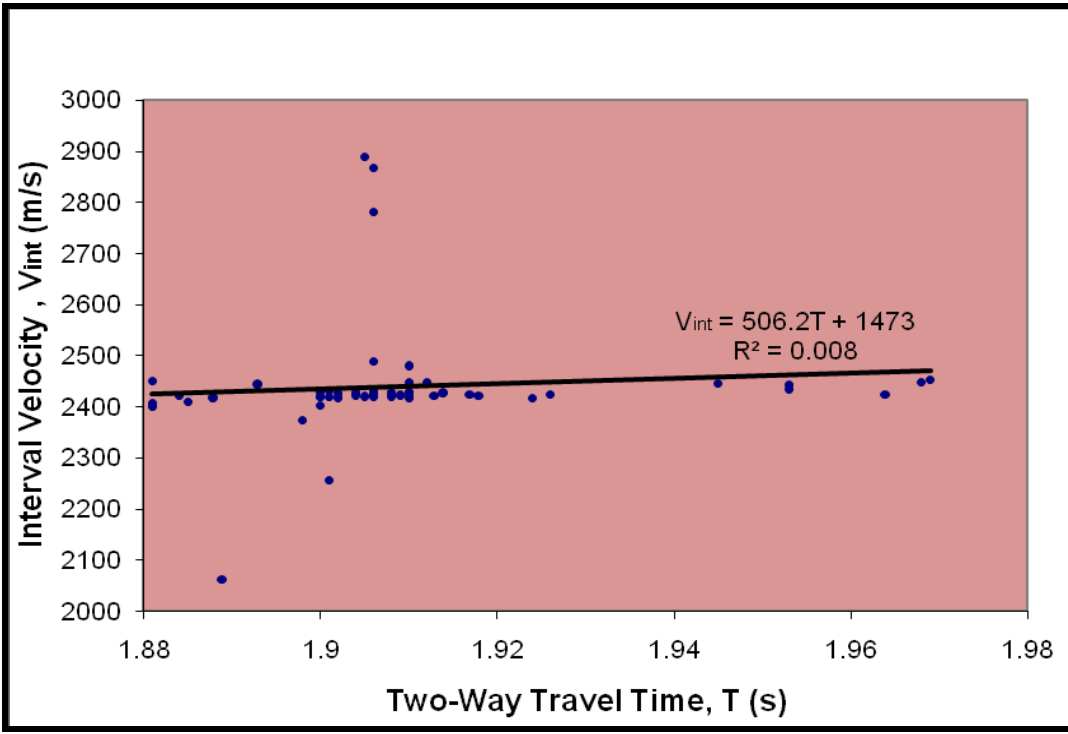

Figure 10: Agbada Field: Interval Velocity versus Two-way Traveltime Crossplot

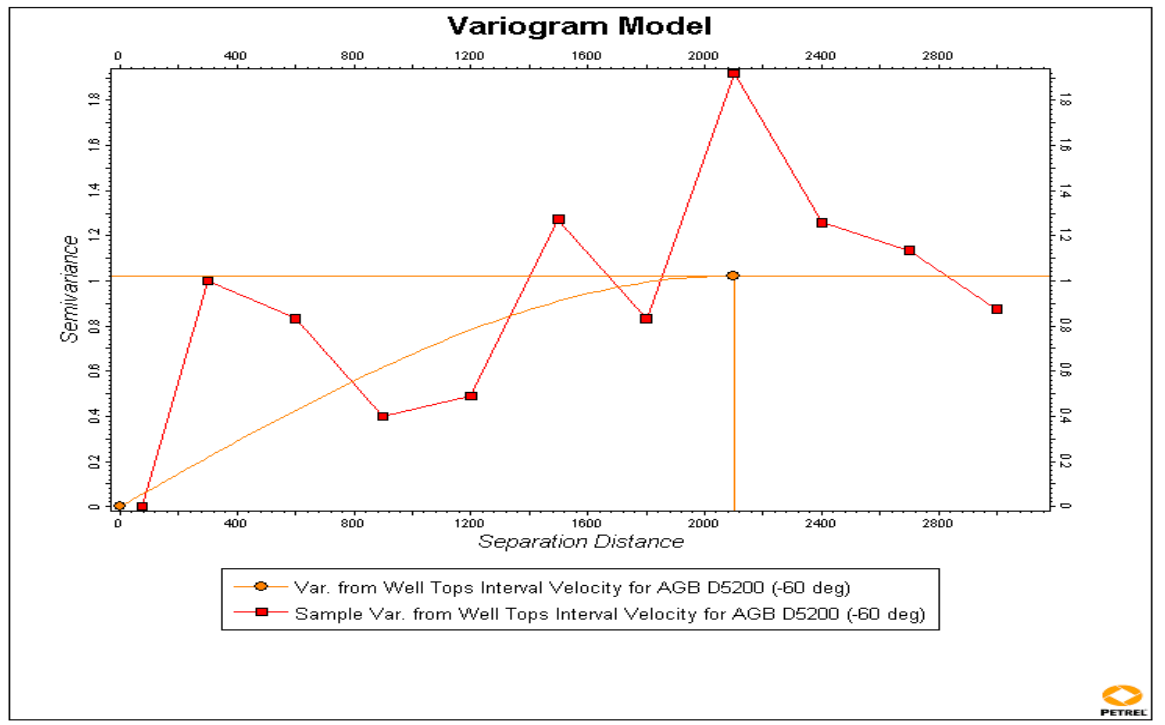

Figure 11: Agbada Field: Variogram model of interval velocity in the direction of maximum variability

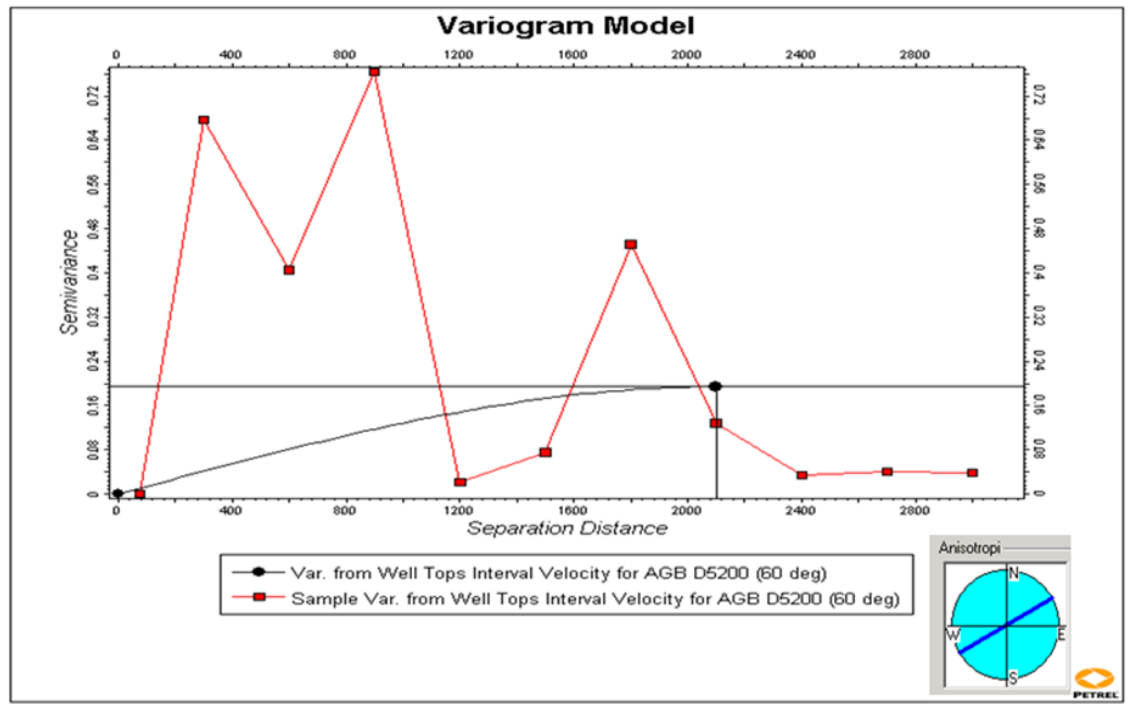

Figure 12: Agbada Field: Variogram model of interval velocity in the direction of minimum variability 


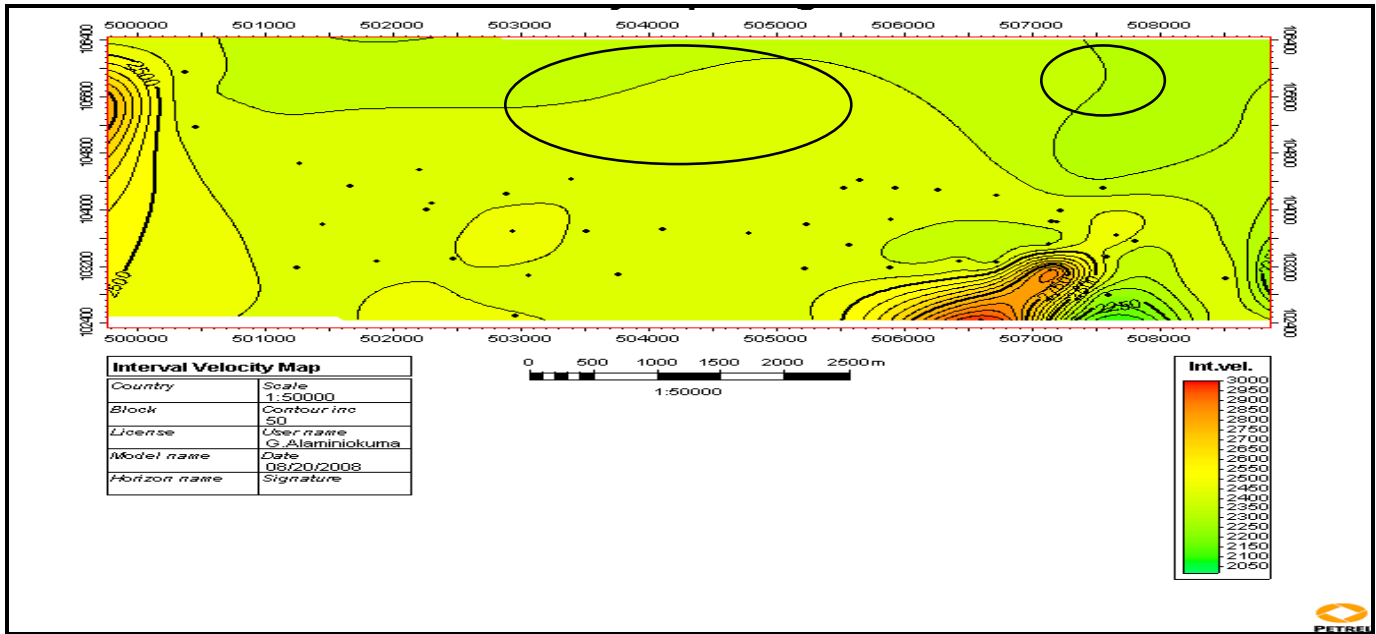

Figure 13 : Agbada Field: Interval velocity map of Top of D5.2 Reservoir across the 60 wells without applying Kriging Algorithm

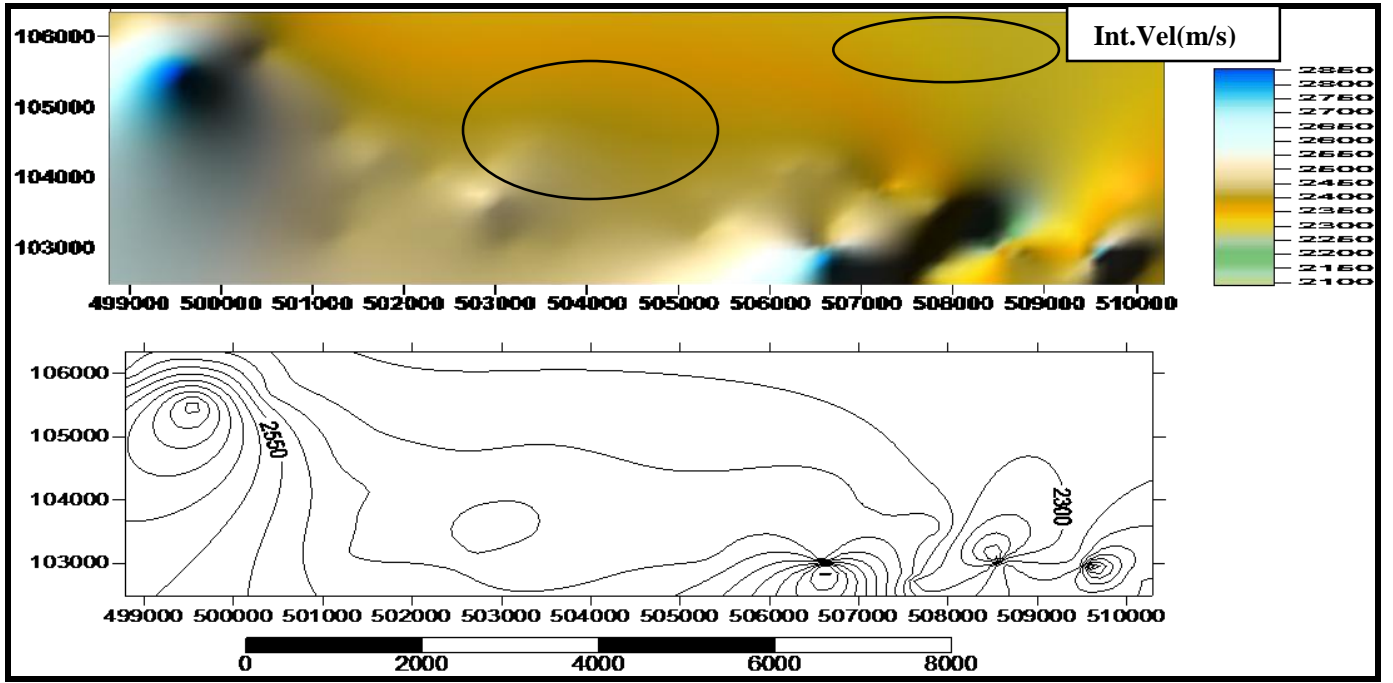

Figure 14 : Agbada Field: Interval velocity map of Top of D5.2 Reservoir across the 60 wells with Kriging Algorithm..

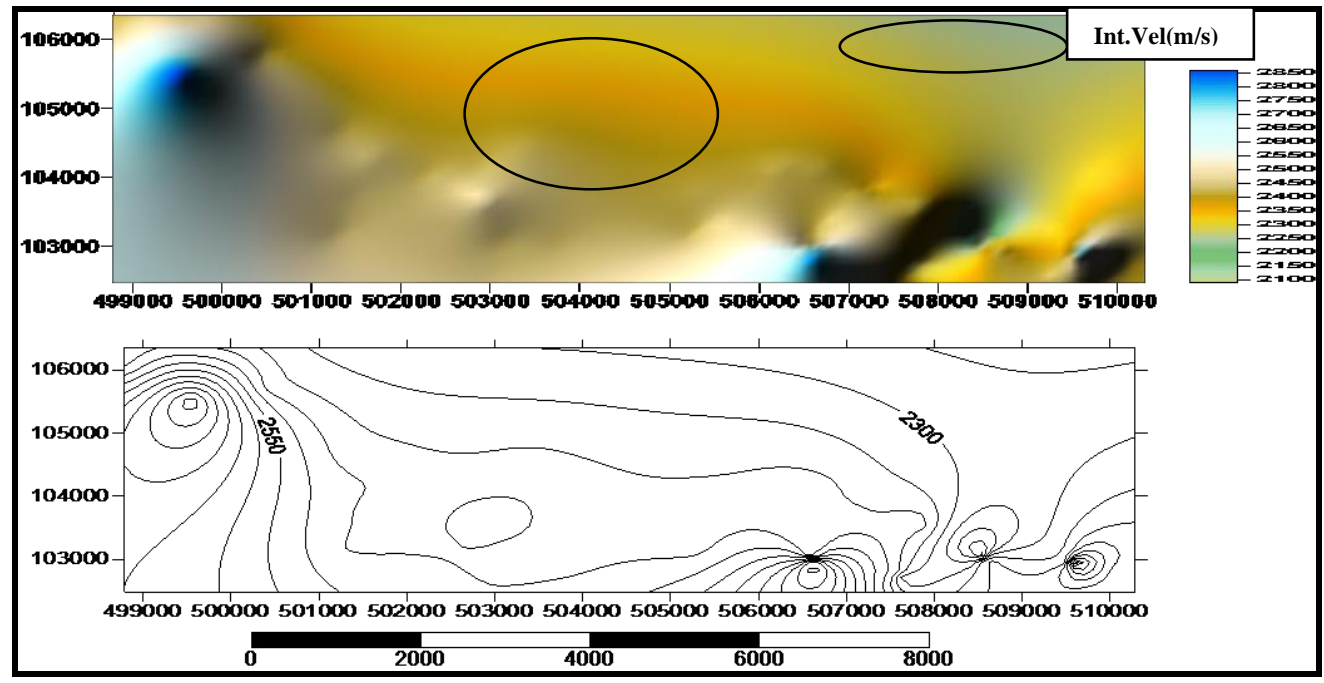

Figure 15 : Agbada Field: Interval velocity map of Top of D5.2 Reservoir across the 60 wells with Kriging with External Drift (KED) Algorithm. The highly prospective zones are in Geen colour,followed by Yellow and Orange colours. This is in view of the velocity pull-down in the presence of hydrcarbon.Lthofacies are also better segmented. 


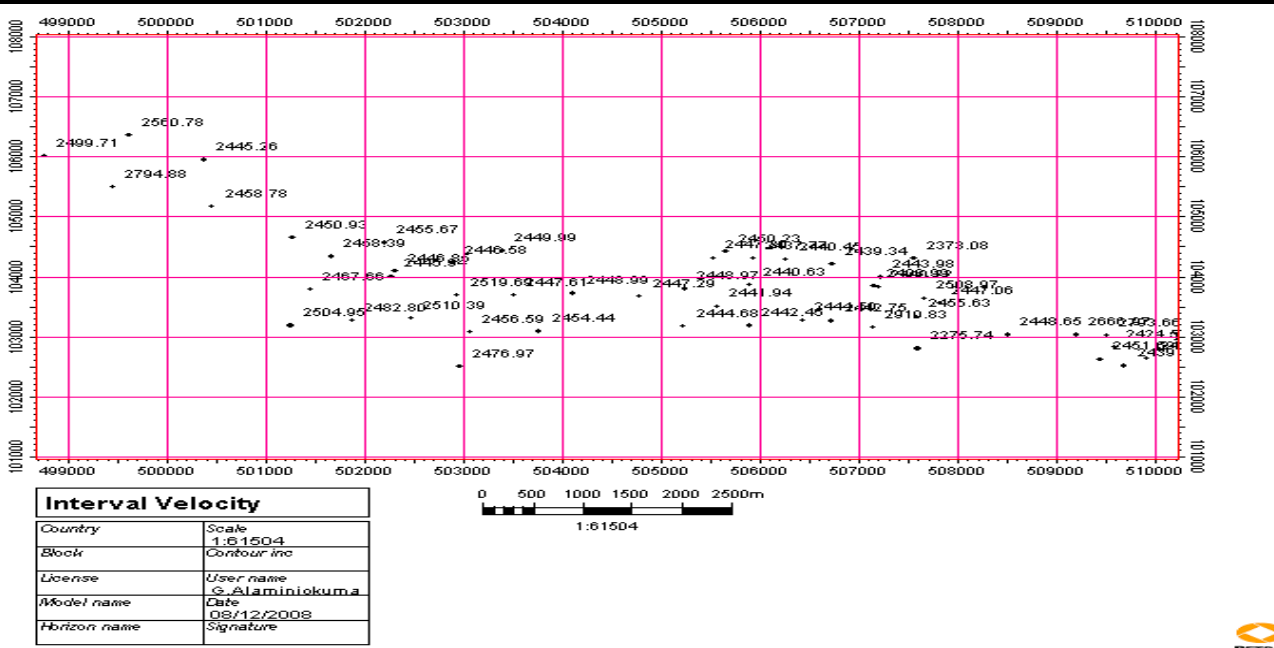

Figure 16: Agbada Field: Interval Velocities picked at 60 well locations at the Top of the D5.2 Reservoir (Shown again for well location identification)

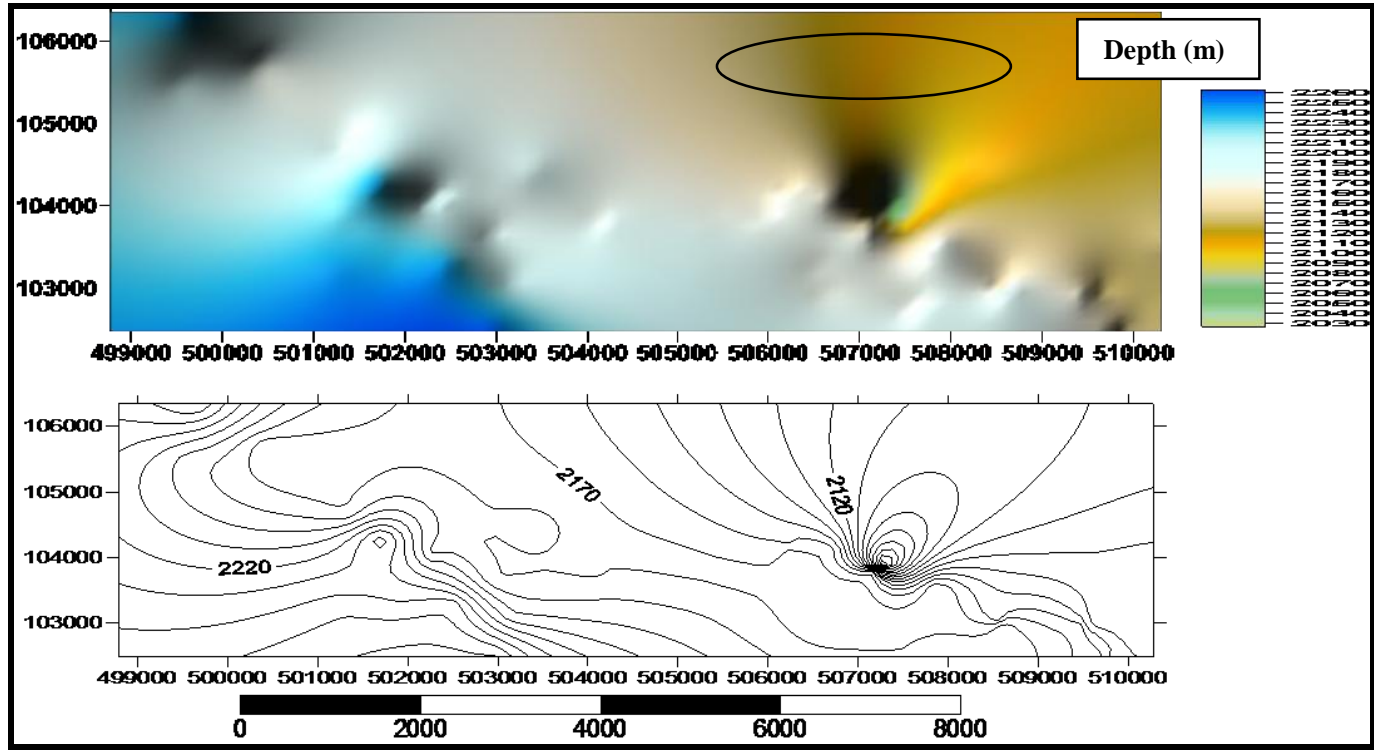

Figure 17: Agbada Field: Depth Map of Top of D5.2 Reservoir with Kriging

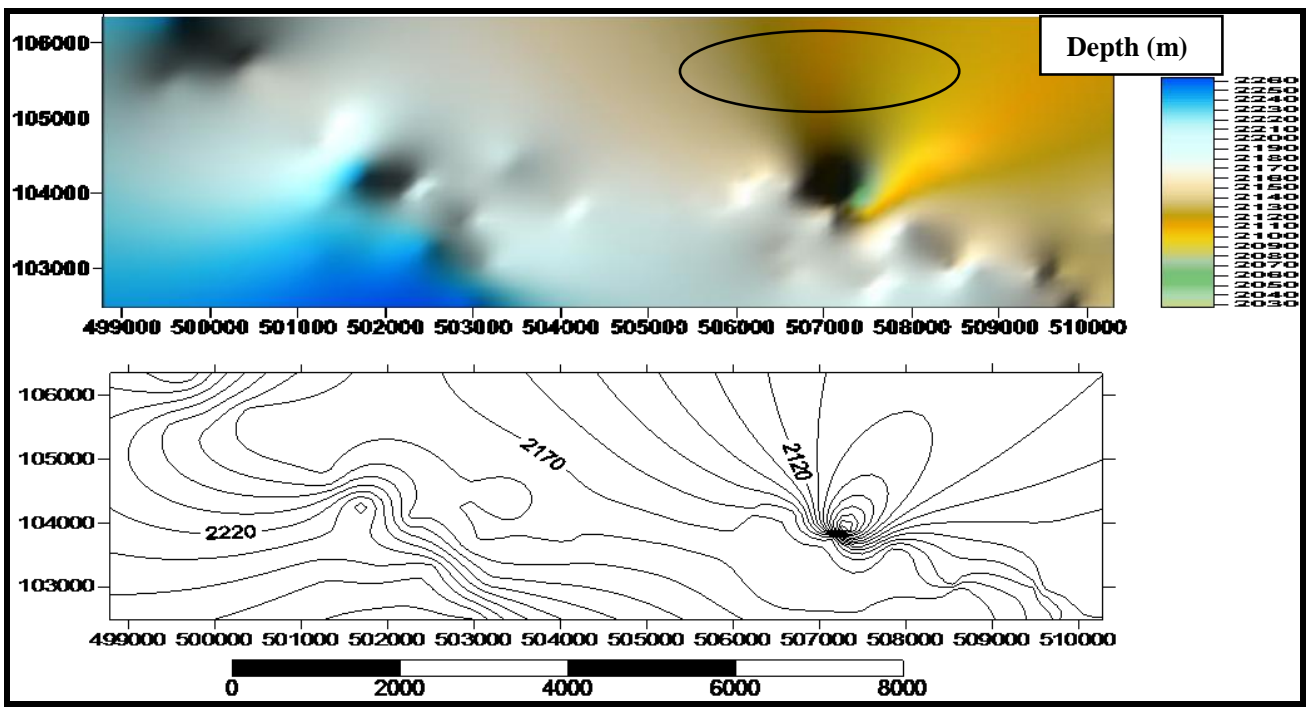

Figure 18 : Depth Map of Top of D5.2 Reservoir with Kriging with External Drift (KED) Algorithm.The map is indicative of a slope. 


\section{Conclusion And Recommendation}

It has been demonstrated that although well data is the best quality data available, it does not allow one to build a velocity model that correctly describes the lateral changes in velocities. This can be explained by its sparseness. Seismic two-way time has better lateral distribution and it has been demonstrated that it can strongly improve the velocity model if it is properly incorporated in a geostatistical manner. In areas of structural or seismic velocity complexity, where conventional assumptions fail, only careful application of 3D prestack depth imaging can be relied on to accurately delineate geological structure, aid risk assessment, and help operators to improve drilling success rates. Developing a geostatistical model of velocity in time-to-depth conversion of the Niger Delta reservoirs will essentially improve the depth structural framework for the quantification of the masked or bypassed hydrocarbon for possible re-development of the fields in the Niger Delta.

\section{References}

[1]. Armstrong, T., McAteer, J. and Connoly, P. (1999). Removal of Overburden Velocity Anomaly Effect for Depth Conversion, EAGE, Helsinki, 3 - 33

[2]. Avbovbo, A. A., (1978).Tertiary lithostratigraphy of Niger Delta.American Association of Association of Petroleum Geologists, Tulsa, Oklahoma, p. 96-200.

[3]. Chambers, R., Yarus J. and Hird, K. (2000). Petroleum Geostatistics for Non-Geostatisticians (Part 2). The Leading Edge ,Geologic Column. p $592-599$

[4]. Coleou, T (2001). On the Use of Seismic Velocities in Model Building for Depth Conversion. CGG, UK. EAGE 63 ${ }^{\text {rd }}$ Conference \& Technical Exhibition - Amsterdam, The Netherlands

[5]. Doust, H. \& Omatsola, E., 1989. Geology of the Niger Delta. American Association of Petroleum Geologists, Volume 48, pp. 201238.

[6]. Dubrule, O. (1998). Geostatistics in Petroleum Geology. American Association of Petroleum Geologist (AAPG) Continuing Education Course Notes, No. 38

[7]. Francis, A. (2002). An Introduction to Geostatistics. Earthworks Environment \& Resources Ltd., Salisbury, United Kingdom.

[8]. Goovaerts, P. (1997). Geostatistics for Natural Resources Evaluation. Oxford University Press, New York. 483 pp.

[9]. Hohn, M. E., (1998): Geostatistics and Petroleum Geology, Kluwer Publishers, second edition, 248 p.

[10]. Hwang, L. and McCorkindale, D. (1994). Troll Field Depth Conversion Using Geostatistically Derived Average Velocities. The Leading Edge, Vol. 13, Pg. 262-269.

[11]. Isaaks, E. H and Srivastava (1990), An Introduction to Applied Geostatistics (Oxford University Press.

[12]. Joumel. A,. 1989. Fundamentals of Geostatistics in five lessons: American Geophysical Union.

[13]. Leuangthong, O., McLennan, J. A., \& Deutsch, C. V. (2004). Minimum acceptance criteria for geostatistical realizations. Natural Resources Research, 13, 131-141.

[14]. Lima, H. M. (2005). Geostatistics in Reservoir Characterization: From Estimation to Simulation Methods. Estudios Geol. 61: 135 145

[15]. Merki, P. J. (1972). Structural Geology of the Cenozoic Niger Delta. In: Dessauvagie, T. F. J. and Whiteman, A. J. (eds), African Geology, University of Ibadan Press, Nigeria. pp. 635-646.

[16]. Schlumberger (2017) Oil Services Limited. 5599 San Felipe St, Houston, TX 77056 Stacher, P., 1995. Present understanding of the Niger Delta hydrocarbon habitat, in, Oti, M.N and Postma, G., (eds.), Geology of Deltas: Rotterdam, A. A. Balkema, p. 257-267.. s.l.:s.n.

[17]. Tuttle, Michele; Charpentier, Ronald; Brownfield, Michael. "The Niger Delta Petroleum System:Niger Delta Province, Nigeria, Cameroon, and Equatorial Guinea, Africa". United States Geologic Survey. United States Geologic Survey. 2015.

[18]. Weber, K.J. and Dakorou, E.M. (1975). Petroleum Geological aspect of the Niger Delta, Journal of mining and Geology, 12, pp 912.

[19]. Weber, K. J. (1987), "Hydrocarbon distribution patterns in Nigeria Growth fault structure controlled by structural style and stratigraphy”, Journal of Petroleum Sciences and Engineering, Vol. 1,PP. 91-104. 